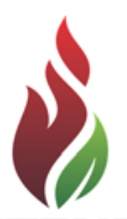

SUSTENERE

Publishing Corporation
ZRBADM

Journals Homepage:

www.sustenere.co/journals

\section{UTILIZAÇÃO DO EYETRACKING PARA ANÁLISE DE INTERAÇÃO DE USUÁRIOS DE BAIXO E ALTO LETRAMENTO}

\section{RESUMO}

Usuários com perfil de baixo letramento, em geral, possuem dificuldade em entender informações textuais, devido à deficiência nas habilidades de leitura escrita, cálculo e ciências. A maioria dos problemas de usabilidade na Web está relacionada a encontrar, ler e compreender a informação. Pessoas com baixos níveis de habilidade de leitura têm esses problemas ampliados devido à falta de competências linguísticas, caracterizando, assim, uma questão de acessibilidade. O presente trabalho analisou a interação, de usuários com dois perfis diferentes: alto e de baixo letramento, por meio de um dispositivo de rastreamento ocular Tobii, modelo T120. A tecnologia de eyetracking, através de raios infravermelhos, grava as fixações visuais de usuários em tempo de interação. A partir dessa avaliação foram apontadas, de forma comparativa, suas experiências e caraterísticas de interação dos dois perfis de usuários, com um site comercial popular. A relevância deste trabalho, ao testar a interação de usuários analfabetos funcionais, foi propor melhorias de interface de sistemas que permitam o acesso a todos os usuários, independe do grau de instrução. Os resultados sugerem que diante das diferenças na navegação de usuários com perfis distintos de letramento, a partir de algumas correções e adaptações nas interfaces, é possível acessibilizar e promover a participação cidadã

PALAVRAS-CHAVES: Usabilidade; Acessibilidade; Analfabetismo Funcional; Rastreamento Ocular.

\section{USING EYETRACKING TO ANALYSE HIGH-LITERATE AND LOW-LITERATE USER INTERACTION}

\begin{abstract}
Users with low literacy profile, in general, have difficulty understanding textual information, due to the deficiency in reading skills, numeracy and science. Most usability problems on Web is related to find, read and understand the information. People with low levels of reading ability have magnified these problems due to lack of language skills, thus featuring an accessibility issue. This study examined the interaction of users with two different profiles: high, low literacy, using a Tobii eyetracking device, model T120. The eyetracking technology, using infrared rays, records the visual fixations of users in interaction time. From this evaluation were identified, comparatively, their experiences and characteristics of interaction of the two user profiles with the popular shopping site. The relevance of this work to test the interaction of functionally illiterate users, was to propose improvements of interface systems that allow access to all users, independent of the level of education. The results suggest that given the differences in navigation of users with different profiles of literacy, from some corrections and adjustments of interfaces, it is possible acessibilizar and promote citizen participation.
\end{abstract}

KEYWORDS: Usability; Accessibility; Functional Illiteracy; Eyetracking.
Revista Brasileira de

Administração Científica,

Aquidabã, v.5, n.2, Out 2014.

ISSN 2179-684X

SECTION: Articles

TOPIC: Sistemas e Tecnologia da Informação

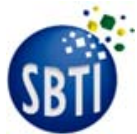

Anais do Simpósio Brasileiro de Tecnologia da Informação (SBTI 2014)

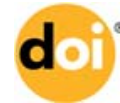

DOI: 10.6008/SPC2179-684X.2014.002.0002

Letícia Régis Di Maio

Universidade Federal do Estado do Rio de Janeiro, Brasil http://lattes.cnpq.br/1282834635639484 leticia.maio@uniriotec.br

Ney Wagner Freitas Cavalcante Universidade Federal do Estado do Rio de Janeiro, Brasil http://lattes.cnpq.br/3669112309107873 ney.cavalcante@uniriotec.br

Simone Bacellar Leal Ferreira Universidade Federal do Estado do Rio de Janeiro, Brasil http://lattes.cnpq.br/0926018459123736 simone@uniriotec.br

José Luiz dos Anjos Rosa

Centro Universitário Estadual da Zona Oeste, Brasil http://lattes.cnpq.br/1071027809772193 jrosa@uezo.ri.gov.b

Denis Silva da Silveira

Universidade de Pernambuco, Brasil http://lattes.cnpq.br/3799501798859187 dsilveira@ufpe.br

Received: 13/08/2014

Approved: 15/10/2014 Reviewed anonymously in the process of blind peer.

\section{Referencing this:}

DI MAIO, L. R.; CAVALCANTE, N. W. F.; FERREIRA, S. B. L.; ROSA, J. L. A.; SILVEIRA, D. S.. Utilização do eyetracking para análise de interação de usuários de baixo e alto letramento. Revista Brasileira de Administração Científica, Aquidabã, v.5, n.2, p.17-32, 2014. DOI: http://dx.doi.org/10.6008/SPC2179$684 \times .2014 .002 .0002$ 


\section{INTRODUÇÃO}

O aumento dos meios de comunicação de massa e de novas tecnologias provocou mudanças decisivas nos processos e comportamento da comunicação humana. Por conta disso, os pesquisadores e desenvolvedores têm novos desafios, uma vez que as interfaces precisam ser acessíveis a todos os perfis de usuários, incluindo aqueles com limitações relacionadas à alfabetização. Tais limitações podem comprometer a interação, principalmente porque o conteúdo disponível na Web é essencialmente textual (KODAGODA \& WONG, 2008).

Esses usuários têm peculiaridades que devem ser consideradas nos projetos de desenvolvimento e design de sites, tais como limitações de percepção de conteúdo e estratégias de busca (KODAGODA et al., 2009; GUPTA \& ROSÉ, 2010). A maioria dos problemas de usabilidade na Web está relacionada a encontrar, ler e compreender a informação (NIELSEN \& LORANGER, 2007). Pessoas com baixos níveis de habilidade de leitura têm esses problemas ampliados devido à falta de competências linguísticas, sendo caracterizada também como uma questão de acessibilidade. Além disso, usam a Web de forma diferente dos usuários com habilidades de leitura (KODAGODA \& WONG, 2008; CAPRA et al., 2012; MODESTO \& FERREIRA, 2013).

O objetivo desta pesquisa foi analisar, por meio do rastreamento ocular, o comportamento de dois grupos de usuários, com alto e baixo letramento, identificando experiências e caraterísticas de sua interação com um site comercial popular. Para atingir o objetivo, foram realizados testes, com o apoio de um dispositivo de eyetracking Tobii T120, executando uma tarefa pré-determinada em um site comercial, e como resultado, foi gerado uma lista de sugestões de melhoria da interface com foco em pessoas com baixo letramento, ou seja, pessoas com menos de quatro anos completos de estudo.

\section{REVISÃO TEÓRICA}

\section{Rastreamento Ocular}

Eyetracking permite fazer o rastreamento dos movimentos oculares do observador através de raios infravermelhos, registrando o percurso percorrido pelo olhar, os pontos que mais chamaram a atenção do usuário, os dados do tempo que levam para tomar uma decisão e qual a hierarquia que estabelecem na ordem de visualização (FERREIRA, 2009; BARBOZA, 2011).

Uma vez que rastreia o caminho percorrido pelos olhos, pode apoiar o desenvolvimento e aperfeiçoamento de interfaces (NIELSEN \& PERNICE, 2009), que, (FERREIRA \& NUNES, 2008) se bem projetadas, podem tornar-se uma fonte de motivação ou um fator decisivo para a rejeição do sistema em caso contrário. 


\section{Alfabetização}

A definição sobre o que é analfabetismo vem, ao longo das últimas décadas, sofrendo revisões significativas, como reflexo das próprias mudanças sociais (IPM, 2001). Um entendimento comum sobre a alfabetização envolve vocabulário, leitura e escrita, além de habilidades como lógica, matemática, análise simbólica (imagens e sons) e interpretação de texto (UNESCO, 2006).

A Organização das Nações Unidas para a Educação, Ciência e Cultura (UNESCO) (MODESTO et al., 2013) considera como analfabetos funcionais, pessoas com deficiência nas habilidades de leitura, escrita , cálculo e ciências, cujo nível de escolaridade é equivalente a menos de quatro anos completos de estudo. Essa classificação, adotada pelo Instituto Nacional de Estudos e Pesquisas Educacionais Anísio Teixeira (INEP) e do Instituto Brasileiro de Geografia e Estatística (IBGE) (UNESCO, 2006) foi utilizada no estudo.

De acordo com a agência brasileira, a taxa de analfabetismo funcional no ano de 2013 no Brasil foi estimada em $20 \%$ do total, ou seja, 29 milhões de pessoas (MODESTO et al., 2013). O conceito de analfabetismo funcional varia de região para região. Hoje em dia é uma abordagem comum considerar que essas habilidades devem ser contextualizadas e que não são desenvolvidas igualmente entre indivíduos diferentes. Além disso, conceito de alfabetização também considera os aspectos funcionais, que significam capacidade de aplicação de vocabulário, leitura e escrita em diferentes áreas da vida diária, como na computação, ecologia, saúde e outras áreas (UNESCO, 2006).

Capra e demais (CAPRA et al., 2012) recomendam que os participantes (analfabetos funcionais) de uma pesquisa sejam chamados de "usuários de baixo letramento", uma vez que um dos protocolos utilizados para orientar o seu estudo recomendou não chamá-los de analfabetos funcionais. Esse conceito será utilizado nesse trabalho. É importante considerar os analfabetos funcionais como usuários potenciais e propor soluções tecnológicas acessíveis para esse público, considerando as diretrizes de acessibilidade (MELO et al., 2009).

Uma das dificuldades dos usuários com baixa escolaridade é a compreensão de um texto. Chama-se inteligibilidade a característica do texto que faz com que ele seja fácil de ser lido e compreendido. Textos fáceis podem compensar os baixos níveis de conhecimento prévio, habilidade de leitura, interesse e motivação (BARBOZA, 2011). Sendo assim, as soluções propostas devem ser adequadas não só a um público mais letrado, garantindo assim que um texto seja facilmente lido e compreendido pelos analfabetos funcionais (CAPRA et al., 2012). 


\section{Trabalhos Relacionados}

No estudo que Harper (HARPER et al., 2013) realizou com usuários de alto e baixo letramento, o uso de rastreamento ocular é justificado em função da maioria das fixações ocorrerem em intervalos de tempo de milissegundos, o que torna relativamente difícil a comparação de comportamento apenas por observação direta.

Em sua pesquisa, Ferreira (FERREIRA, 2009) fez um estudo comparativo entre usuários na retenção e processamento de informação para diferentes grupos e layouts. A autora realizou o cruzamento de dados entre os resultados do eyetracking e do inquérito sobre processamento do conteúdo de uma revista. Porém, todos os usuários eram universitários, o que torna mais difícil obter resultados discrepantes.

Koller e demais (KOLLER et al., 2012) sugerem o eyetracking como ferramenta complementar na pesquisa de marketing, além de propor duas áreas específicas em que o equipamento pode ajudar o pesquisador: no pré-teste de questionários, e como ferramenta de controle para manipulações em ambientes experimentais. No entanto, os autores não fizeram testes com usuários.

\section{METODOLOGIA}

\section{Seleção do Perfil dos Usuários que Participaram da Pesquisa}

A presente pesquisa, de caráter exploratório, foi baseada no método qualitativo de coleta de dados consistindo em seis etapas, descritas a seguir. Foram escolhidos dez adultos, formando dois grupos distintos: um formado por pessoas com baixo letramento e outro com alto. Este número foi definido tendo em conta as recomendações propostas na pesquisa de Nielsen (NIELSEN, 2000), que identificou que cinco usuários são capazes de detectar $85 \%$ dos problemas de usabilidade; à medida que o número de usuários aumenta, a informação que é recolhida tende a se repetir, proporcionando uma menor quantidade de informações novas.

O primeiro grupo foi composto de cinco adultos com escolaridade de até três séries completas de ensino, ou seja, menos de quatro anos de estudos completos de acordo com a classificação da UNESCO (UNESCO, 2006). O segundo grupo foi composto de cinco adultos alfabetizados plenamente e com cinco anos de estudo ou mais. Todos os participantes possuem conhecimentos básicos em navegação na Web de no mínimo três meses e possuem idades entre 18 a 64 anos. 


\section{Seleção do Site e Definição de Tarefas}

Foi escolhido um site comercial de loja de óculos, 'Óticas do Povo' de acordo com o perfil dos usuários e selecionado com base na familiaridade com as suas lojas físicas. $O$ teste foi formado por uma tarefa múltipla, composta de dois passos: no primeiro passo o participante devia encontrar no Google o site das 'Óticas do Povo' e, no segundo uma vez que ele tivesse localizado o site em questão, ele deveria achar o endereço de uma loja em um bairro específico da cidade que a pesquisa foi realizada.

\section{Escolha do Modelo Equipamento de Eyetracker}

Foi selecionado o modelo Tobii T120 que permite (FERREIRA, 2009): calibração em segundos; não é invasivo, pois permite que os usuários se comportem naturalmente na visualização, como perante qualquer outro monitor; possibilita realizar longos e precisos estudos sem fadiga ocular; recolhe dados de qualquer pessoa, sem restrições para quem usa óculos ou lentes de contato; garante a qualidade de registro, independente das condições de luminosidade no ambiente onde se realiza o teste.

\section{Estudo de Caso}

Foi feito um estudo de caso com dois grupos, executando uma tarefa múltipla (uma parte no Google e outra no site da loja).

\section{Análise dos Dados}

A tecnologia do eyetracking gera resultados complementares aos testes tradicionais de usabilidade, com relatórios sobre a navegação dos usuários (TOBII, 2013). Os dados oriundos desse tipo de teste apresentam formatos variados (quantitativos, estatísticos, de imagem e de vídeo), sinalizando o caminho percorrido durante a navegação, de forma sequencial e com indicativos de duração em cada ponto de fixação dos olhos do participante, podendo detectar onde houve maior esforço cognitivo e prováveis problemas de usabilidade não explorados.

\section{Sugestão de Melhoria de Interface para Usuários de Baixo Letramento}

Durante a análise de dados, alguns comportamentos e dificuldades comuns aos usuários de baixo letramento foram percebidos e, em virtude disso, foi gerada uma lista com sugestões de melhorias para este público. 


\section{Estudo de Caso}

Foram enviados convites para participação da pesquisa de acordo com o perfil educacional dos usuários para associações, universidades e centros comunitários. Os testes foram realizados em ambiente de laboratório controlado. Antes das observações com os dez voluntários, foi aplicado um teste piloto, com um usuário-teste de modo a se fazer alguns ajustes e se preparar o ambiente de teste. A tarefa do teste piloto foi a mesma das demais observações.

Todos participantes assinaram um termo de consentimento para participarem da pesquisa que foi lido em voz alta pelos pesquisadores, além de terem sido fornecidos esclarecimentos sobre a pesquisa. Após isso, os participantes responderam a um questionário impresso que foi utilizado para a classificação do perfil, de acordo com a escolaridade declarada. Em seguida, o equipamento de eyetracking foi apresentado e cada participante teve os olhos calibrados pelo aparelho, além de receberem as devidas orientações sobre postura, concentração para evitar possíveis perdas de registros pelo rastreador.

Explicou-se a tarefa exigida no teste, bem como a liberdade e a esperada autonomia que o usuário teria para a execução da mesma, antes de qualquer solicitação de ajuda aos pesquisadores. Para garantir o anonimato dos participantes, seus nomes foram codificados da seguinte forma: BL_01, BL_02, BL_03, BL_04 e BL_05 para o grupo com baixo letramento e AL_01, AL_02, AL_03, AL_04 e AL_05, para usuários com alto letramento. A tabela 1 apresenta o perfil dos participantes e o tempo total de execução da tarefa, contando as duas fases da tarefa.

Tabela 1: Perfil dos participantes.

\begin{tabular}{l|l|l}
\hline Usuário & Idade & Tempo total para conclusão da tarefa múltipla \\
\hline BL_01 & 59 & $05 \min$ e 22s \\
\hline BL_02 & 64 & $10 \min$ e 03s \\
\hline BL_03 & 58 & $06 \min$ e 55s \\
\hline BL_04 & 62 & $06 \min$ e 49s \\
\hline BL_05 & 59 & $05 \min$ e 26s \\
\hline AL_01 & 36 & $34 \mathrm{~s}$ \\
\hline AL_02 & 35 & $36 \mathrm{~s}$ \\
\hline AL_03 & 38 & $36 \mathrm{~s}$ \\
\hline AL_04 & 40 & $44 \mathrm{~s}$ \\
\hline AL_05 & 33 & $39 \mathrm{~s}$ \\
\hline
\end{tabular}

Com o objetivo de melhor compreender o conteúdo lógico e estratégico que levou cada usuário a tomar uma decisão durante a realização da tarefa, seja por um erro, desvio ou distração, solicitou-se que os participantes verbalizassem seus pensamentos após a sessão de avaliação, ou seja, adotou-se o protocolo de verbalização consecutiva. Não se optou pela verbalização simultânea, pois de acordo com 'Protocolos de Avaliação de Acessibilidade Web com Analfabetos Funcionais', proposto por Capra (CAPRA, 2011; CAPRA et al., 2012), a verbalização simultânea é uma barreira para usuários de baixo letramento. Após os ajustes iniciais, iniciaram-se os testes, que continham a mesma tarefa do teste piloto, com os dez usuários. Um vídeo dos testes foi gravado pelo rastreador e, em paralelo, os pesquisadores fizeram anotações utilizando a técnica 
de observação direta, simultaneamente às gravações do rastreamento. Foram dadas as orientações sobre a tarefa e emissão de comentários positivos para estimular o usuário a continuar o teste.

O tempo para completar a tarefa foi estabelecido entre os pesquisadores, mas desconhecido pelos usuários buscando naturalidade durante a interação. A tarefa deveria ser concluída em até dez minutos, porém os pesquisadores só poderiam oferecer ajuda após os cinco primeiros minutos. Após o término da tarefa, ocorreu o preenchimento de um questionário sobre a realização da mesma e uma rápida entrevista com o usuário sobre o processo de interação com o site e a funcionalidade da tarefa.

\section{Análise de Dados}

O rastreador ocular pode gerar variados tipos de relatórios, a partir das associações das métricas do equipamento com as áreas de interesse. Após os testes, foram determinadas, pelos pesquisadores, as áreas de interesse (Areas Of Interest) para indicar quais partes da interface seriam relevantes para a pesquisa. As áreas de interesse serão tratadas, no presente trabalho, pela abreviatura: AOI. As AOls foram escolhidas, a partir do recurso de 'mapa de calor' (heat map), que registrou as áreas que chamaram mais a atenção dos participantes, bem como os elementos de interface que poderiam receber interação dos usuários para que concluíssem a tarefa.

Dentre as métricas sugeridas pelo rastreador ocular, os pesquisadores selecionaram cinco que pudessem gerar dados relevantes para a pesquisa, como descrito no Quadro 1. A partir dessas métricas, durante a navegação dos participantes, foi feito um levantamento de dados para posterior comparação com os relatórios gerados pelo eyetracking.

Quadro 1: Descrições das métricas.

\begin{tabular}{|l|l|}
\hline Métricas & Descrições das Métricas \\
\hline FFD (First Fixation Duration) & Duração em segundos da primeira fixação em uma AOI \\
\hline FC (Fixation Count) & Número de vezes que o participante se fixa em uma AOI \\
\hline MCC (Mouse Click Count) & Número de cliques do mouse de um participante em uma AOI \\
\hline TTFF (Time To First Fixation) & Tempo, desde o início do estímulo, até a primeira fixação em uma AOI \\
\hline TTFMC (Time To First Mouse Click) & Tempo até o primeiro clique do mouse de um participante em uma AOI \\
\hline
\end{tabular}

Um exemplo do mapa de calor pode ser visto na figura 1, na qual as áreas em vermelho indicam maior tempo de retenção do olhar, variando entre os tons de laranja e amarelo, até as áreas em verde, nas quais os usuários pouco se fixaram.

Em seguida, foram extraídos os dados quantitativos do eyetracker, com o cruzamento feito a partir das ocorrências de fixações dos usuários nas áreas de interesse demarcadas. Foram exportadas as gravações com as interações dos usuários (com as expressões faciais dos usuários, durante os testes). Foram exportados os vídeos de rastreamento que, como o auxílio do 
recurso do 'caminho percorrido pelo olhar' (gaze plot) indicaram os pontos exatos de fixação registrados pelo rastreamento. Um exemplo do gaze plot pode ser conferido na figura 2.

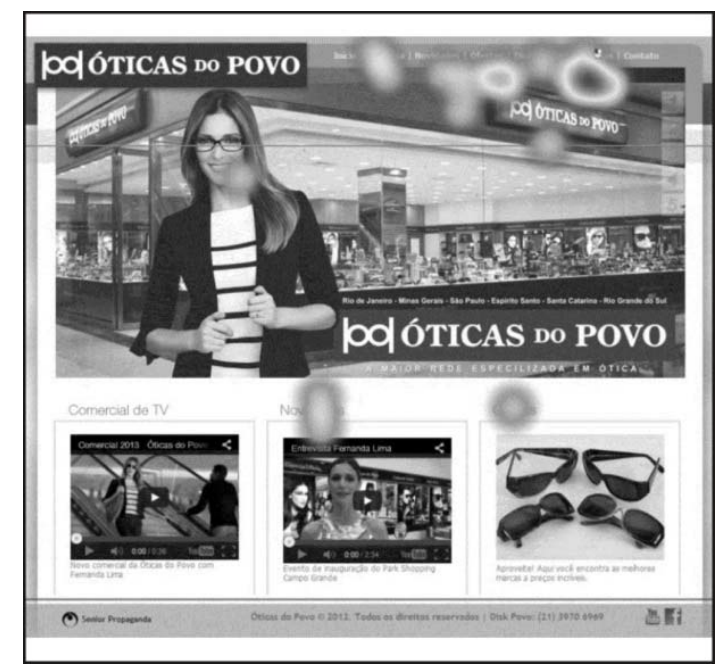

Figura 1: Recurso do mapa de calor.

Os pesquisadores delimitaram as AOls referentes aos dois sites da tarefa múltipla (Google e Óticas do Povo), nomeando-as de acordo com os elementos de interface respectivos, como apresentado no quadro 2.

Quadro 2: Descrições das AOls (áreas de interesse)

\begin{tabular}{|l|l|}
\hline AOl's & Descrições das AOl's \\
\hline bt_gg & botão pesquisa Google \\
\hline bti_gg & botão pesquisa Google inferior \\
\hline cp_gg & campo de pesquisa Google \\
\hline cpi_gg & campo de pesquisa Google - página interna \\
\hline cps_gg & campo de pesquisa superior Google \\
\hline lh_st & link homepage do site \\
\hline ld_gg & link divergente Google \\
\hline sp_gg & sugestão de pesquisa (text area) \\
\hline ml_op & menu lojas Óticas do Povo \\
\hline bc_op & banner central Óticas do Povo \\
\hline bi_op & banner inferior Óticas do Povo \\
\hline mi_op & mapa imagem Óticas do Povo \\
\hline mt_op & mapa texto Óticas do Povo \\
\hline el_op & endereço loja Óticas do Povo \\
\hline cf_op & Ctrl + F Óticas do Povo \\
\hline
\end{tabular}

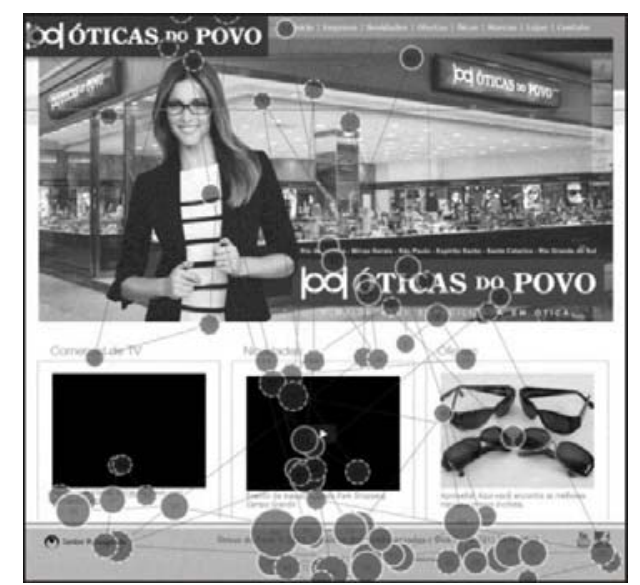

Figura 2: Recurso do gaze plot do usuário BL_03. 
Páginas densas, com muitas informações e links também confundem os usuários, que apresentam dificuldades tanto para visualizar informações que não estão no local que estão focalizando, bem como para fazer uma leitura superficial da página de modo a terem uma visão abrangente do que é apresentado (KODAGODA et al., 2009).

Devido à baixa legibilidade (em tamanho de fonte e contraste com a cor de fundo) o rótulo do menu 'lojas' demorou a ser reconhecido pelos usuários de baixo letramento, que primeiro rastrearam informações textuais com maior atratividade, por exemplo, os banners da figura 2 (comercial de TV; novidades; ofertas), bem como as imagens da página inicial. Esse fato foi percebido pela análise de gaze plot, como mostrado na figura 2, na qual vê-se que o usuário BL_03 se dispersou em 84 fixações, antes de perceber o menu no canto superior da página.

\section{Observações Feitas Durante a Tarefa Múltipla}

$1^{\circ}$ Passo (busca no site google): A partir das métricas TTFF (Time To First Fixation) e TTFMC (Time To First Mouse Click), associadas às AOls bt_gg (botão Pesquisa Google) e cp_gg (campo de pesquisa Google), pode-se observar que dois usuários de baixo letramento clicaram no botão, antes de digitarem algo no campo de pesquisa. O usuário BL_01, por exemplo, clicou no botão aos 12 segundos e só clicou no campo aos 53 segundos. Já o usuário BL_05 clicou no botão aos 15 segundos e no campo aos 27 segundos. Em entrevista pós-teste, ambos afirmaram acreditar que só assim poderiam começar a pesquisa no Google.

Para os usuários de alto letramento a primeira interação com o sistema foi com a $\mathrm{AOI}$ cp_gg (campo de pesquisa Google). A partir dessas métricas, pode-se observar que, para concluir o primeiro passo (chegar à página inicial do site 'Óticas do Povo'), os usuários de baixo letramento gastaram, em média, 356 segundos, enquanto que os de alto letramento levaram 26 segundos, ou seja, estes últimos foram em média 13,6 vezes mais rápidos.

O site do motor de busca Google apresenta resultados de pesquisa em três tipos de informações: a primeira parte é uma linha composta pelo título da página de destino, em forma de link e na cor azul; a segunda é uma linha (posicionada logo abaixo do link) em forma de URL (Uniform Resourse Locator) na cor verde, com o endereço da página de destino; a terceira parte contém a descrição do conteúdo, onde os termos pesquisados aparecem destacados em negrito.

Considerando que o link é composto de palavras-chave da pesquisa feita pelo usuário e que, nem sempre a URL associada ao link corresponde ao endereço esperado pelo usuário, percebeu-se que o participante de baixo letramento se confunde com essa análise de resultados.

Para exemplificar, na figura 3, o usuário BL_04, após ter pesquisado as palavras "otica do povo de campo grande", confundiu um dos links, ignorando que a URL o conduziria a outro site, nem percebendo que o site oficial estava posicionado mais abaixo. 


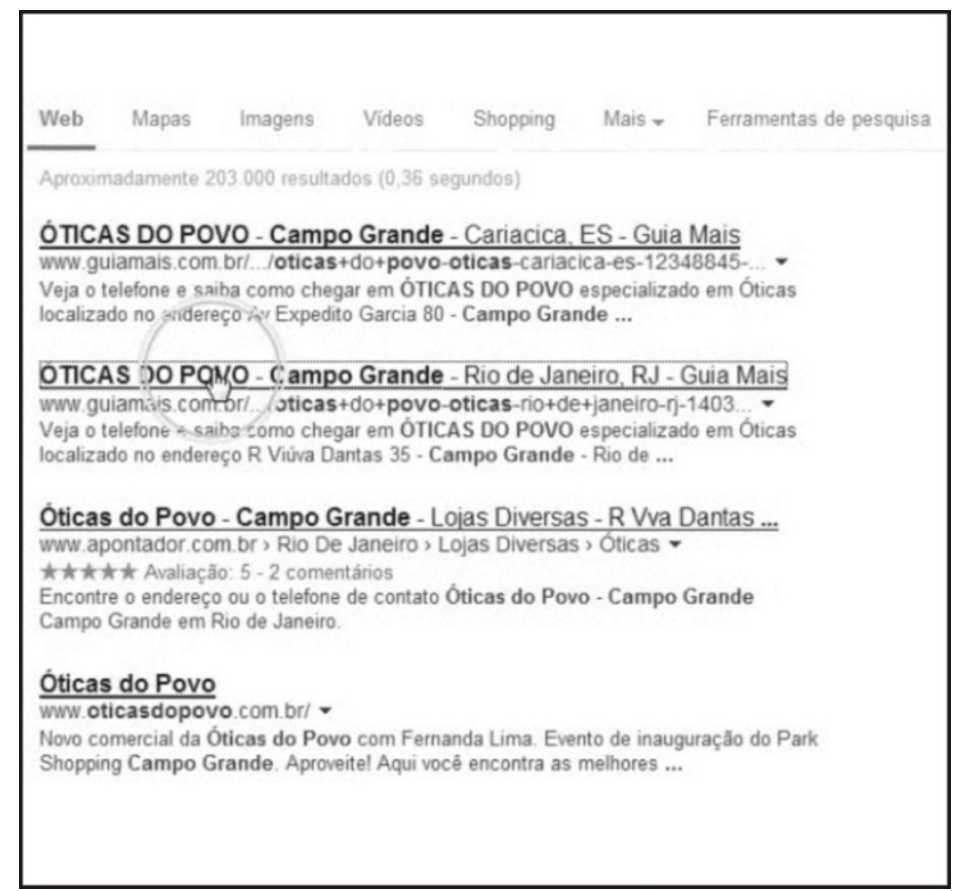

Figura 3: BL_04 clica no link de outro site.

Este registro foi feito a partir das métricas TTFF (Time To First Fixation) e TTFMC (Time To First Mouse Click) com as AOls Id_gg (link divergente do Google) e Ih_st (link homepage do site).Como os participantes de baixo letramento possuem dificuldade de transferir sua atenção rapidamente de um assunto para outro sem se perderem, no momento em que digitavam, eles só conseguiam manter o foco no campo de entrada de texto ou no teclado (MODESTO, 2012). Essa observação pode ser verificada a partir do caminho percorrido pelo olhar (gaze plot) que mostra ter havido mais fixações nos links, do que nas URL's.

A partir das métricas FFD (First Fixation Duration) e MCC (Mouse Click Count) foi possível observar que a AOI Id_gg (link divergente do Google), referente a outro site, teve menor tempo de atenção para os usuários de baixo letramento, que fixaram o olhar nesse link por 0,11 segundos, em média. Já os usuários de alto letramento tiveram fixações de 0,32 segundos, em média e não clicaram no link do site concorrente, optando pelo link do site esperado na tarefa. Isto poderia justificar o fato da maioria dos usuários de baixo letramento ter se confundido com os sites concorrentes, necessitando reiniciar a tarefa.

Em virtude do maior tempo de fixação sobre a AOI "link divergente do Google", observouse que os usuários de alto letramento não se dispersaram com o link do site concorrente e focaram melhor na tarefa. Foi possível observar que todos os usuários de baixo letramento se confundiram com os links divergentes para sites concorrentes, em detrimento à atenção que deveriam ter aos links das páginas iniciais do site proposto nesta tarefa. Sendo assim, todos necessitaram reiniciar a tarefa.

A tendência de abandonar a busca também foi percebida quando se dão por satisfeitos com suas pesquisas, ainda que não tenham obtido o melhor ou mais correto resultado, o que coincide com as pesquisas de Modesto (MODESTO, 2012). Já a maioria dos usuários de alto 
letramento desprezou os links divergentes, tendo sido mais atentos aos objetivos propostos nas tarefas.

$2^{\circ}$ passo (busca no site Oticas do Povo): Navegaram pela página inicial do site os cinco usuários de baixo letramento e apenas três do outro grupo. Desses oito usuários, todos visualizaram a AOI ml_op (menu lojas Óticas do Povo), porém, em tempos diferentes.

De acordo com os registros da linha do tempo do rastreador, e a partir métrica TTFF (Time To First Fixation), entre o surgimento da AOI ml_op (menu lojas Óticas do Povo) e o momento da primeira fixação sobre esta $\mathrm{AOI}$, os usuários de alto letramento foram 37,5 vezes mais rápidos para perceber este estímulo visual. Em contrapartida, com o auxílio da métrica FC (Fixation Count), foi possível registrar que, antes de localizarem o referido menu, os usuários de baixo letramento rastrearam informações textuais que apresentavam fontes em tamanho maior, bem como algumas imagens.

O registro das fixações sobre a AOI ml_op (menu lojas Óticas do Povo), a partir da associação das métricas TTFF (Time To First Fixation) e TTFMC (Time To First Mouse Click) indicou que o intervalo de tempo entre o estímulo visual do menu e a consequente interação dos usuários sobre este elemento de interface foi maior para os usuários de baixo letramento (88 segundos, em média) em comparação com o intervalo dos usuários de alto letramento (1 segundo, em média).

Pode-se, assim, perceber que os usuários de baixo letramento são mais suscetíveis a problemas de interface relacionados à falta de legibilidade, que apresenta um tamanho reduzido da fonte e um baixo contraste de cor. Isso foi registrado na entrevista pós-teste, quando dois participantes de baixo letramento (BL_04 e BL_05) foram questionados sobre alguma sugestão de melhoria do site, apesar de já terem escrito no questionário que não teriam, mas na entrevista eles disseram que o tamanho das letras poderia ser maior e que não estavam enxergando direito por causa das cores.

A partir da métrica FC (Fixation Count), observou-se que, apesar do rastreador ter registrado dezessete fixações sobre a AOI ml_op (menu lojas Óticas do Povo), por parte do usuário BL_04, este não associou o rótulo do menu ao objetivo da tarefa. Apesar disso, associando a métrica FC (Fixation Count) à AOI bi_op (banner inferior Óticas do Povo), correspondente ao banner promocional "Ofertas" (com imagens de óculos), este mesmo usuário fez 28 fixações nesse banner, acreditando ser o caminho para chegar aos endereços das lojas. Sua intenção ficou clara na verbalização consecutiva, quando este usuário afirmou: - "Eu estava tentando entrar na ótica pela foto da vitrine da loja. Os endereços deviam estar lá dentro".

A figura 4 ilustra essa intenção, que foi constatada no vídeo, o clique do mouse sobre o referido banner promocional, após 4 min e 15s do início da tarefa. Quando o usuário clicou nesse link, foi direcionado para uma página de ofertas, tendo se frustrado, ainda mais, por não encontrar os endereços das lojas. 


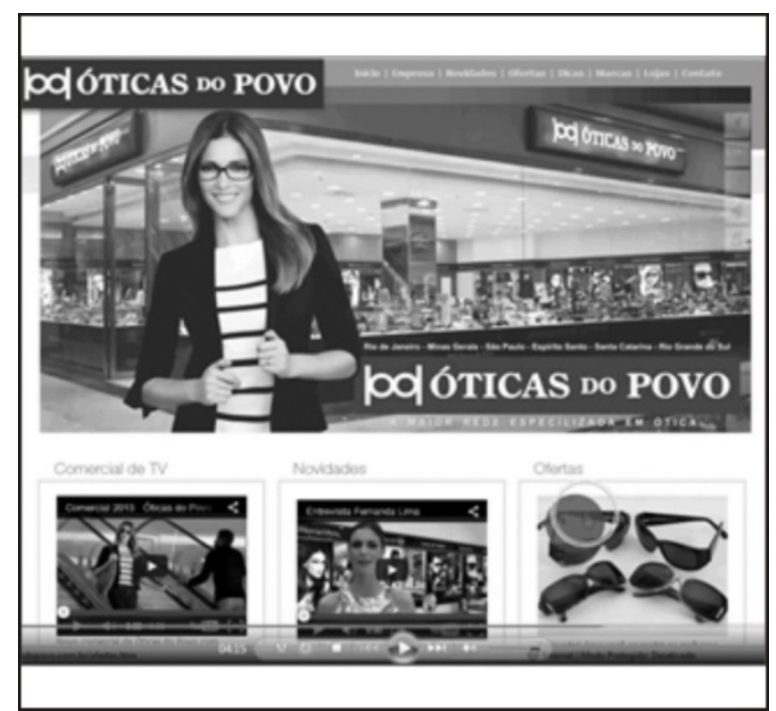

Figura 4: BL_04 clica no banner promocional para 'entrar' na ótica pela vitrine e encontrar os endereços.

A figura 5 ilustra as fixações do usuário BL_04 que antecederam ao clique do mouse sobre a AOI ml_op (menu lojas Óticas do Povo). Esse clique só ocorreu na 153a fixação, aos 5 min e 27s (mais da metade do tempo para realizar a tarefa), quando este usuário recebeu ajuda dos pesquisadores para voltar a navegar no menu horizontal superior, interagir com o menu "lojas" e cumprir a tarefa.

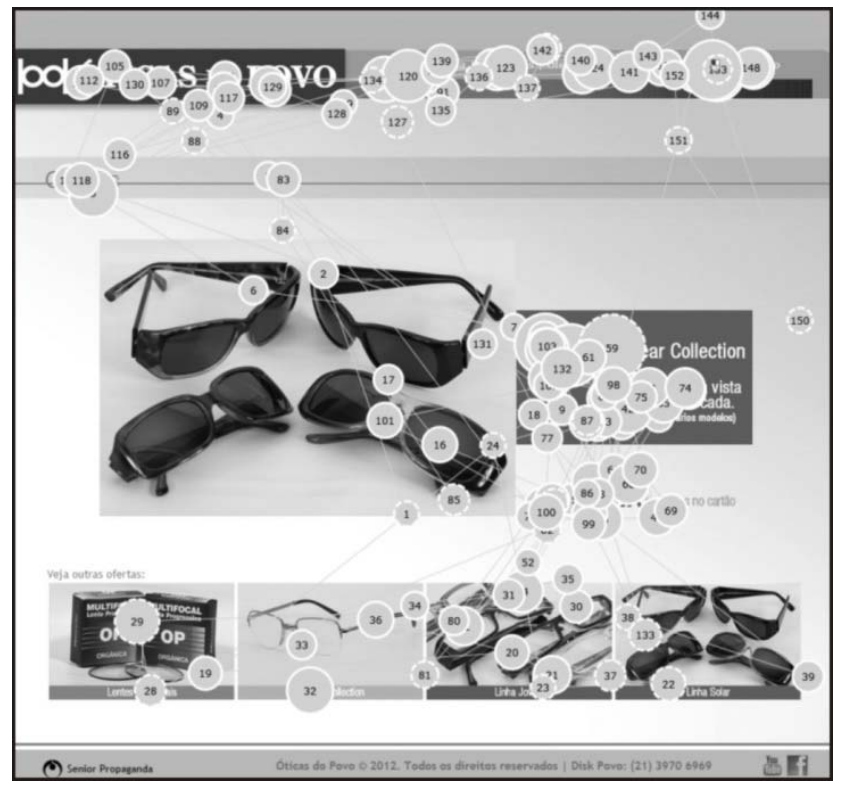

Figura 5: Registro das 152 fixações de BL_04 antes de clicar no menu lojas, com auxílio dos pesquisadores.

Esse mesmo banner promocional 'Ofertas' recebeu, em média, seis fixações dos outros quatro usuários de baixo letramento, mas foi ignorado pelos usuários do outro grupo.Ao clicarem no botão 'lojas', os usuários foram direcionados para uma página intermediária que contém um mapa do Brasil indicando os cinco estados nos quais há lojas "Óticas do povo". Na página aberta com o mapa, três usuários de baixo letramento (BL_01, BL_02 e BL_05) tiveram fixações sobre a AOI mt_op (mapa texto Óticas do Povo), que identifica os textos dos estados brasileiros, mas 
também tiveram rápidas fixações sobre a AOI mi_op (mapa imagem Óticas do Povo), que identifica as divisões geográficas.

Com o mouse sobre dos estados de Minas e do Espírito Santo, esses três usuários tentavam identificar se essas imagens eram clicáveis. Na verbalização consecutiva, dois desses usuários (BL_01 e BL_02) comentaram que "o mapa confundiu, porque os estados eram parecidos". Já os usuários de alto letramento se alternaram entre as duas AOls marcadas, tanto na imagem que indicava o estado do Rio de Janeiro, como na sua descrição textual.

Do grupo de alto letramento, dois usuários (AL_04 e AL_05) também interpretaram o mapa como um elemento de interação, passando o mouse sobre ele. Com o auxílio da métrica MCC (Mouse Click Count) sobre a AOI mi_op (mapa imagem Óticas do Povo), pode-se observar que o usuário AL_05 tentou interagir com a imagem do mapa, supondo que a mesma fosse link para os endereços das lojas, no intuito de tentar cumprir a tarefa. Diante da frustração, clicou na AOI mt_op (mapa texto Óticas do Povo) com o nome do estado e conseguiu chegar à página pretendida.

Na página do mapa, pode-se registrar que as affordances não foram tratadas com o devido cuidado, pois a imagem do mapa sugeria uma interação, mas somente os nomes dos estados eram links que levavam à página de endereços do site. As falsas affordances podem dar a impressão de que a interface funciona de uma determinada maneira, quando na verdade funciona de outra forma (Barbosa \& Silva, 2010).

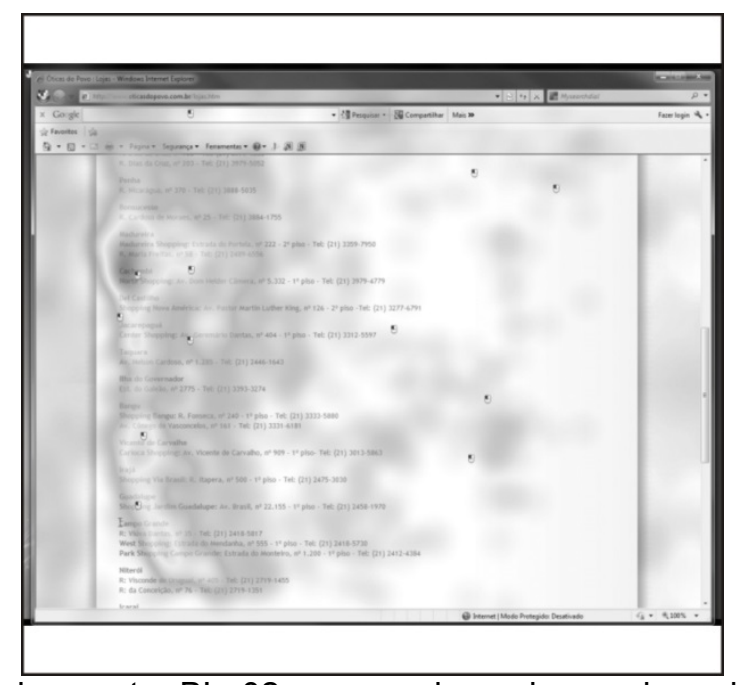

Figura 6: Mapa de calor demonstra BL_02 navegando em busca do endereço proposto na tarefa.

Quando chegaram, finalmente, à página de endereços das lojas "Óticas do povo", os usuários encontraram a lista de endereços disposta de forma aleatória. A falta de ordenação alfabética confundiu os usuários de baixo letramento, aumentando o tempo para a conclusão da tarefa, que foi, em média, 41,6 segundos. A partir da métrica TTFF (Time To First Fixation), associada à AOI el_op (endereço loja Óticas do Povo), foi possível registrar a diferença de tempo entre a chegada à página com os endereços das lojas Óticas do Povo e a primeira fixação sobre o endereço da loja do bairro de Campo Grande (proposto na tarefa). A figura 6 demonstra, por meio 
do mapa de calor, o usuário BL_02 navegando por toda a página antes de localizar o endereço proposto, o que se deu, de acordo com a métrica TTFF (Time To First Fixation), após 79s.

Já os usuários de alto letramento, fizeram uso de outros recursos para localizar o endereço pretendido: teclas de atalho (identificadas pela AOI cf_op (Ctrl + F Óticas do Povo)) e barra de rolagem do site, sem comprometer seus desempenhos. O resultado indica que o grupo de alto letramento foi 4,16 vezes mais rápido para concluir a etapa final da tarefa.

\section{Sugestões de Melhoria de Interface para Usuário de Baixo Letramento}

Seguem algumas sugestões para possíveis melhorias de interfaces voltadas para esse perfil de usuário: Os rótulos dos elementos de interface devem ser objetivos e claros, além de legíveis para evitar a indução ao erro. Sugere-se a substituição do rótulo do menu 'lojas' por 'endereços'; Selecionar um tamanho de fontes maior para os textos; Selecionar as cores do site de modo a exibirem um bom contraste; Selecionar imagens e banners de forma criteriosa. Esses elementos podem induzir o usuário a erros; O volume de dados deve ser minimizado; é importante reduzir a quantidade de informações nos sites; Sugere-se dispor os endereços das lojas por ordem alfabética; Recomenda-se o uso filtros nos mecanismos de busca para facilitar a localização de dados da página, como nome da loja, bairro, telefone entre outros; Desaconselhase o uso de página intermediária, entre uma interação com algum item de menu e o objetivo final do usuário, pois essa página intermediária apenas aumenta a carga de trabalho e pode acarretar na desistência da navegação; Deve-se evitar falsas affordances, poupando esses usuários da frustração em interagir com elementos que sugiram ações diferentes dos seus propósitos.

\section{CONCLUSÕES}

\section{Principais resultados}

Os resultados do eyetracking indicaram diferenças na navegação de usuários com perfis distintos de letramento. Com o auxílio das métricas do rastreamento ocular, principalmente pela quantidade e duração das fixações, foi possível mensurar o grau de dificuldade que usuários de baixo letramento têm para navegar, indicando que este perfil, lêem absolutamente todo o texto das páginas de modo a terem segurança na tomada de decisão e que as imagens, quando não contextualizadas, podem ser fatores de dispersão.

\section{Limitações}

Existem outros critérios que poderiam ser utilizados no estudo, em vez de considerar apenas os anos de estudo na educação formal. Algumas instituições desenvolveram testes de alfabetização e numéricos específicos, com níveis de dificuldade e pontuação, para avaliar as 
habilidades das pessoas em leitura, escrita, cálculos e ciências. No entanto, estes testes são privados, não existindo ferramentas públicas que permita classificar os usuários desta forma (CAPRA et al., 2012). O estudo poderia apresentar outros resultados se o perfil dos participantes fosse mais delineado, bem como a faixa etária fosse menos abrangente.

\section{Trabalhos Futuros}

Recomenda-se, para trabalhos futuros, testar interfaces de sistemas de serviços públicos e utilizar um número maior de usuários para realizar um tratamento estatístico dos dados. Outra recomendação é ampliar os perfis dos participantes analfabetos funcionais, dividindo-os em subgrupos de acordo com algumas características específicas: faixa etária, sexo e nível de inclusão digital.

\section{REFERÊNCIAS}

BARBOSA, S. D. J.; SILVA, B. S.. Interação humano-computador. Rio de Janeiro: Elsevier, 2010.

BARBOZA, E. M. F. A .. linguagem clara em conteúdos de websites governamentais para promover a acessibilidade a cidadãos com baixo nível de escolaridade. Revista do Instituto Brasileiro de Informação em Ciência e Tecnologia, v.6, n.1, 2011.

CAPRA, E. P.. Protocolos de Avaliação de Acessibilidade Web com Analfabetos Funcionais. Dissertação (Mestrado em Informática) - Universidade Federal do Estado do Rio de Janeiro, Rio de Janeiro, 2011.

CAPRA, E. P.; FERREIRA, S. B. L.; SILVEIRA, D. S.; MODESTO, D.. Evaluation of web accessibility: an approach related to functional illiteracy. Procedia Computer Science, Lisboa, v.14, p.36-46, 2012.

FERREIRA, S. B. L.; NUNES, R. R.. E-usabilidade. Rio de Janeiro: LTC, 2008.

FERREIRA, S.. Design e processamento cognitivo de informação online: um estudo de eye tracking. Dissertação (Mestrado em Multimídia) - Faculdade de Engenharia da Universidade do Porto, Porto, 2009.

GUPTA, N. K.; ROSÉ, C. P.. Understanding instructional support needs of emerging internet users for web based information seeking. Journal of Educational Data Mining, p.38-82, 2010.

HARPER, L.; MCMACKEN, M.; APPELT, L.; SUMMERS, K.. The importance of choice design for low literate user experience. Communications in Computer and Information Science, v.374, p.430-434, 2013.

KODAGODA, N.; WONG, B.. Effects of low \& high literacy on user performance in information search and retrieval. The British Computer Society, Swinton, p.173-181, 2008

KODAGODA, N.; KAHAN, N.; WONG, W.. Identifying information seeking behaviors of low and high literacy users: combined cognitive task analysis. London: 2009. p.347-354.

KOLLER, M.; SALZBERGER, T.; BRENNER, G.; WALLA, P.. Broadening the range of applications of eyetracking in business research: ampliando o leque de aplicações de eye-tracking na pesquisa em Administração. Revista de Administração da PUCRS, v.23, n.1, p.71-77, 2012.

MELO, A.; PICCOLO, L.; ÁVILA, I.; TAMBASCIA, C.. Usabilidade, acessibilidade e inteligibilidade aplicadas em interfaces para analfabetos, idosos e pessoas com deficiência. In: SIMPÓSIO BRASILEIRO SOBRE FATORES HUMANOS EM SISTEMAS COMPUTACIONAIS. 8. Anais. São Paulo, 2009. 
MODESTO, D. M.. Acessibilidade de Recursos em uma Interface de Motor de Busca com Foco em Usuários com Baixo Letramento. Tese (Mestrado em Informática) - Universidade Federal do Estado do Rio de Janeiro, Rio de Janeiro, 2012.

MODESTO, D. M.; FERREIRA, S. B. L.; ALVES, A. S.. Search Engine Accessibility for Low-Literate Users - In $5^{\text {th }}$ Int. Conf. on Human-Computer Interaction, 2013.

NIELSEN, J.; LORANGER, H.. Usabilidade na Web: Projetando Websites com Qualidade. Rio de Janeiro: Elsevier, 2007.

NIELSEN, J.; PERNICE, K.. Eyetracking Web Usability. Berkeley, 2009.

UNESCO. United Nations Educational, Scientific and Cultural Organization. Understandings of Literacy. Literacy for Life, p.149-159, 2006. 